\title{
Perancangan Aplikasi Pengolahan Citra Digital Untuk Menentukan Bibit Unggul Biji Kopi dengan Metode Canny Edge Detection
}

\author{
Sandrak A Batubara \\ Prodi Teknik Informatika, STMIK Budi Darma, Medan, Indonesia \\ Email: sandrak13@gmail.com \\ Submitted 15-05-2020; Accepted 01-06-2020; Published 14-06-2020
}

\begin{abstract}
Abstrak
Citra biji kopi sangatlah penting untuk dikenali, dengan adanya citra biji kopi akan membuat para pecinta kopi lebih gampang untuk mengenali biji-biji kopi hanya dengan melihat citranya tanpa harus kelokasi dimana kopi tersebut tumbuh. Kopi adalah minuman dikenal di indonesia pendeteksian biji kopi sangatlah penting sebab banyaknya biji-bijian yang mirip dengan biji kopi dengan begitu proses untuk mendeteksi biji kopi sangatlah diperlukan agar dapat biji kopi dapat diidentifikasikan, dengan adanya metode cany akan dapat mendetksi biji kopi asli. Metode cany adalah metode yang dapat mendetesi biji kopi dengan cara mengenali biji kopi tersebut.
\end{abstract}

Kata Kunci: Citra Digital, Deteksi Tepi, Bibit Unggul, Metode Cany.

\section{Abstract}

The image of coffee beans is very important to recognize, with the image of coffee beans will make coffee lovers easier to recognize the coffee beans just by looking at their image without having to locate where the coffee grows. Coffee is a beverage known in Indonesia, the detection of coffee beans is very important because the number of seeds that are similar to coffee beans, so the process of detecting coffee beans is very necessary so that coffee beans can be identified, with the method of cany can detect real coffee beans. The cany method is a method that can detect coffee beans by recognizing the coffee beans.

Keyword : Digital Image, Edge Detection, seedlings superior, Cany Method.

\section{PENDAHULUAN}

Deteksi tepi adalah hal yang umum dalam proses pengolahan citra digital karena merupakan salah satu langkah awal dalam melakukan segmentasi citra, yang bertujuan untuk meningkatkan penampakan garis batas suatu daerah atau objek di dalam citra tersebut. Tepi (edge) didefenisikan sebagai batas yang membatasi sebuah daerah dalam image. Deteksi tepi berfungsi untuk mengidentifikasikan garis batas dari suatu objek terhadap latar belakang yang saling tumpang tindih. Sehingga apabila garis tepi pada citra dapat diidentifikasikan dengan akurat, semua objek dapat ditemukan dan sifat dasar seperti area, bentuk, dan ukuran objek dapat diukur [1]. Deteksi tepi menjadi sesuatu yang penting karena manusia dalam mengenali objek tersebut yang membatasi objek-objek yang terdapat dalam citra. Dengan adanya tepi dari objek, mata manusia akan dengan mudah mengenali objek apa yang akan ditampilkan dalam citra tersebut. Tepi dapat diorientasikan dengan suatu arah, dan arah ini berbeda-beda, tergantung pada perubahan intensitas, kopi adalah minuman yang dikenal di indonesia pendeteksian biji kopi sangatlah penting sebab banyaknya bijibijian yang mirip dengan biji kopi dengan begitu proses untuk mendeteksi biji kopi sangatlah diperlukan agar dapat biji kopi dapat diidentifikasikan, dengan adanya metode cany akan dapat mendetksi biji kopi asli. Diperlukan cara untuk mendeteksi jenis-jenis bibit biji kopi dengan teknik edge detection.

Dalam image processing deteksi tepi secara umum dapat dilakukan dengan menggunakan metode Robert, Prewit, Sobel, Canny dan yang akan dibahas dalam skripsi ini adalah pendeteksian tepi dengan menerapkan metode Canny. Namun dalam tekniknya sebelum dilakukan pendeteksian tepi, akan dilakukan terlebih dahulu suatu teknik penapisan citra dengan Gaussian yang bertujuan untuk menghaluskan image atau untuk kepentingan interpolasi tepi objek dalam citra. Untuk itu akan dilakukan operasi penghalusan pada citra sebelum dilakukan pendetaksian tepi (Edge Detection). Dimana, hasil akhir dari penghalusan dengan metode Gaussian akan dilakukan pendeteksian tepi citra dengan menggunakan metode Canny [2].

\section{METODE PENELITIAN}

\subsection{Pengolahan Citra}

Pengolahan citra merupakan bagian penting yang mendasari berbagai aplikasi nyata, seperti pengenalan pola, penginderaan jarak jauh melalui satelit atau pesawat udara, dan machine vision. Pada pengenalan pola, pengolahan citra berperan memisahkan objek dari latar belakang secara otomatis. Selanjutnya, objek akan diproses oleh pengklasifikasi pola [1].

Citra adalah suatu representasi (gambaran), kemiripan, atau imitasi dari suatu objek. Citra terbagi 2 yaitu ada citra yang bersifat analog dan ada citra yang bersifat digital. Citra analog adalah citra yang bersifat kontinu seperti gambar pada monitor televisi, foto sinar X, hasil CT Scan dll. Sedangkan pada citra digital adalah citra yang dapat diolah oleh computer

\subsection{Deteksi Tepi}

Tepi adalah batas antara dua daerah dengan sifat tingkat keabuan yang relatif berbeda. Batas suatu obyek semakin namapak bersamaan dengan ketidak kontinuitasan intensitas dalam suatu citra. Eksperimen pada sistem penglihatan menusia menunjukkan bahwa suatu citra sangat penting, bahkan suatu obyek dapat dikenali hanya dari garis bentuk kasarnya saja (croude ourline). Kenyataan ini merupakan konsep prinsipil untuk mempresentasikan suatu obyek melalui batasnya. Lagi pula, representasi batas mudah untuk diintegrasikan dengan berbagai macam-macam algoritma [2]. 
Deteksi tepi berfungsi untuk memperoleh tepi objek yang memanfaatkan perubahan nilai intensitas

yang drastis pada batas dua area. Defenisi tepi disini adalah "himpunan piksel yang tehubung yang terletak pada batas dua area"(Gonzales \& Woods,2002). Sebuah operator deteksi tepi merupakan operasi betetangga, yaitu sebuah operasi yang memodifikasi nilai keabuan sebuah titik berdasarkan nilai-nilai keabuan dari titik-titik yang ada disekitarnya (tetangganya) yang masing-masing mempunyai bobot tersendiri

\subsection{Metode Canny}

Operator canny dikemukakan oleh Jhon Canny pada tahun 1986, terkenal sebagai operator deteksi tepi yang optimal. Algoritma ini memberikan tingkat kesalahan rendah, melokalisasi titik-titik tepi (jarak pikselpiksel tepi yang ditemukan deteksi dan tepi yang sesungguhnya sangat pendek), dan hanya memberikan satu tanggapan untuk satu tepi [3].

Ada enam langkah yang dilakukan untuk mengimplementasikan deteksi tepi dengan operator canny. Hal ini dilakukan dengan menggunakan operator gaussian.

\section{HASIL DAN PEMBAHASAN}

Citra direpresentasikan dalam bentuk matrik memiliki dimensi yang besar dengan baris dan kolom menunjukkan sebuah titik pada citra serta kesesuaian nilai elemen matrik mengidentifikasikan level pada titik tersebut. Deteksi tepi citra di dasari pada pengenalan tepi dengan menggunakan salah satu operator klasik yaitu mask. Dalam proses pendeteksian tepi pada citra, langkah pertama yang harus dilakukan ialah melakukan input citra, pada sub bab ini 640 x 480 piksel Gambar yang inputkan berupa jpg. Setelah citra kita inputkan maka sistem akan melakukan proses pengambilan nilai piksel masing-masing dari RED, GREEN, dan BLUE (RGB).

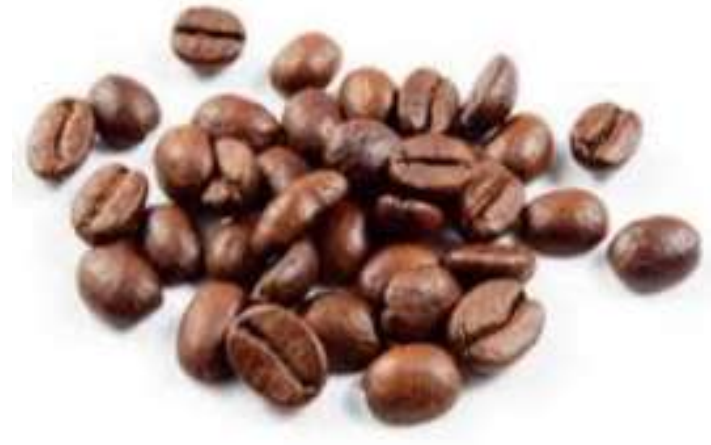

Gambar 1. Citra Biji Kopi

$\left[\begin{array}{ccccc}54 & 61 & 234 & 109 & 235 \\ 199 & 214 & 238 & 236 & 215 \\ 231 & 220 & 216 & 216 & 215 \\ 218 & 218 & 216 & 214 & 213 \\ 208 & 208 & 203 & 205 & 210\end{array}\right]$

Gambar 2. Sampel matriks citra biji kopi 5 x 5

Dari 25 buah piksel di atas merupakan nilai intensitas pada masing-masing channel yang nantinya akan digunakan dalam proses pendeteksian tepi. Analisa proses yang akan dilakukan disini adalah analisa tentang bagaimanaproses deteksi tepi citra digital dengan operator canny. Terdapat enam langkah yang dilakukan untuk mengimplementasikan deteksi tepi canny, yaitu:

\section{Langkah 1 :}

Pertama dilakukan penapisan terhadap citra dengan tujuan untuk menghilangkan derau menggunakan filter Gaussian dengan cadar sederhana dengan ketentuan cadar yang digunakan berukuran jauh lebih kecil daripada ukuran citra.

\section{Langkah 2}

Setelah penghalus gambar terhadap derau dilakukan, selanjutnya proses mendapatkan kekutan tepi (edge strenght) dengan menggunakan operator Gaussian. Gradien citra dapat dihitung dengan rumus:

$|G|=\left|G_{x}\right|+\left|G_{y}\right|$

\section{Langkah 3}

Menghitung arah tepi. Rumus yang digunakan adalah:

theta $=\tan ^{-1}\left(G_{x} G_{y}\right)$

\section{Langkah 4}

Menghubungkan arah tepi dengan sebuah arah yang dapat dilacak citra 


\section{Langkah 5}

Penghilangan non-maksimum dilakukan disepanjang tepi dan menghilangkan piksel-piksel.

\section{Langkah 6}

Proses hysteresis, proses ini menghilangkan garis-garis yang terputus-putus

Berdasarkan penjelasan langkah diatas, untuk mendeteksi tepi dengan metode Canny, kita akan menggunakan gradien $\mathrm{G}(\mathrm{x}, \mathrm{y})$ yang merupakan sebuah vektor yang terdiri dari dua unsur yaitu Gx dan Gy. Deteksi tepi dilakukan dengan cara membaca setiap pixel pada citra dengan cara membaca dari pixel paling kiri atas (timur utara) dan bergerak ke pixel paling kanan bawah (barat selatan). Oleh karena itu, untuk membantu penelusuran tepi, gradien Gx dan Gy masing-masing dihitung dengan matriks operator Canny Mask 3x3. sehingga terbentuk matriks operator canny seperti tabeldi bawah ini:

\begin{tabular}{|c|c|c|c|c|c|c|c|}
\hline \multirow{4}{*}{$C_{x}$} & 1 & 0 & -1 & & -1 & -1 & -1 \\
\cline { 2 - 4 } \cline { 5 - 7 } & 1 & 0 & -1 & $C_{y}$ & 0 & 0 & 0 \\
\cline { 2 - 7 } \cline { 5 - 7 } & 1 & 0 & -1 & & 1 & 1 \\
\hline
\end{tabular}

Gambar 3. Matriks 3x3 operator canny

Sehingga besar gradient dapat di hitung dengan menggunakan persamaan:

$\mathrm{Cx}=(\mathrm{p} 1+\mathrm{cp} 2+\mathrm{p} 3)-(\mathrm{p} 7+\mathrm{cp} 6+\mathrm{p} 5)$

$\mathrm{Cy}=(\mathrm{p} 1+\mathrm{cp} 8+\mathrm{p} 7)-(\mathrm{p} 3+\mathrm{cp} 4+\mathrm{p} 5)$

Rumus Menghitung Gradien:

$|C|=\left|C_{x}\right|+\left|C_{y}\right|$

Berikut adalah hasil perhitungan perkalian matrix penggunaan operator sobel untuk mengetahui segmentasi sebuah gambar citra dengan matrix 5x5. Konvolusi pertama dilakukan terhadap pixel yang bernilai 1 (titik pusat mask).

1. Konvolusi pertama dilakukan terhadap piksel yang bernilai 214 (titik pusat mask):

\begin{tabular}{|c|c|c|c|c|c|c|c|}
\hline 1 & 0 & -1 & 54 & 61 & 234 & 109 & 235 \\
\hline 1 & 0 & -1 & 199 & 214 & 238 & 236 & 215 \\
\hline 1 & 0 & -1 & 231 & 220 & 216 & 216 & 215 \\
\hline \multicolumn{3}{|c|}{ Matrkis $\mathrm{Cx}$} & 218 & 218 & 216 & 214 & 213 \\
\hline-1 & -1 & -1 & 208 & 208 & 203 & 205 & 210 \\
\hline $\begin{array}{l}0 \\
1\end{array}$ & $\begin{array}{l}0 \\
1\end{array}$ & $\frac{0}{1}$ & \multirow{2}{*}{\multicolumn{5}{|c|}{$\square$ Konvolusi Piksel }} \\
\hline & & & & & & & \\
\hline
\end{tabular}

Gambar 4. Konvolusi terhadap piksel 214

Penyelesaian:

$$
\begin{aligned}
& \mathrm{C}_{\mathrm{x}}=(54)(1)+(199)(1)+(231)(1) \quad=484 \\
& (61)(0)+(214)(0)+(220)(0) \quad=0 \\
& (234)(-1)+(238)(-1)+(216)(-1) \quad=-688 \\
& C_{\mathrm{x}}=-204 \\
& \mathrm{C}_{\mathrm{y}}=(54)(-1)+(61)(-1)+(234)(-1) \quad=-349 \\
& (199)(0)+(214)(0)+(238)(0) \quad=0 \\
& \mathrm{C}_{\mathrm{y}}=318 \\
& (231)(1)+(220)(1)+(216)(1) \quad=667 \\
& \text { Nilai Gradien }(\mathrm{Cx}+\mathrm{Cy}) \quad=\mathbf{1 1 4}
\end{aligned}
$$

\begin{tabular}{|c|c|c|c|c|}
\hline$*$ & $*$ & $*$ & 109 & 235 \\
\hline$*$ & 114 & $*$ & 236 & 215 \\
\hline$*$ & $*$ & $*$ & 216 & 215 \\
\hline 218 & 218 & 216 & 214 & 213 \\
\hline 208 & 208 & 203 & 205 & 210 \\
\hline
\end{tabular}

Gambar 5. Nilai gradien konvolusi 214

Keteragan Tabel 3.3, Hasil konvolusi kedua pada nilai piksel 214 menjadi 114 sebagai titik pusat mask Lakukan proses yang sama sampai pada keseluruhan piksel. Adapun hasil konvolusi kesembilan pada nilai piksel 214 menjadi -32 sebagai titik pusat mask. Sesuai dengan persyaratan konvolusi citra jika hasil nilai negatif, maka nilai hasil konvolusi sama dengan "0". 


\begin{tabular}{|c|c|c|c|c|}
\hline$*$ & $*$ & $*$ & $*$ & $*$ \\
\hline$*$ & 114 & 182 & 92 & $*$ \\
\hline$*$ & 0 & 0 & 0 & $*$ \\
\hline$*$ & 0 & 0 & 0 & $*$ \\
\hline$*$ & $*$ & $*$ & $*$ & $*$ \\
\hline
\end{tabular}

Gambar 6. Hasil Matriks 3x3 Operator Canny

Maka hasil deteksi tepi yang didapat dari perhitungan matrix untuk mengetahui segmentasi pada gambar menggunakan metode canny, pendeteksian tepi biji kopi dapat dilihat pada gambar dibawah ini:

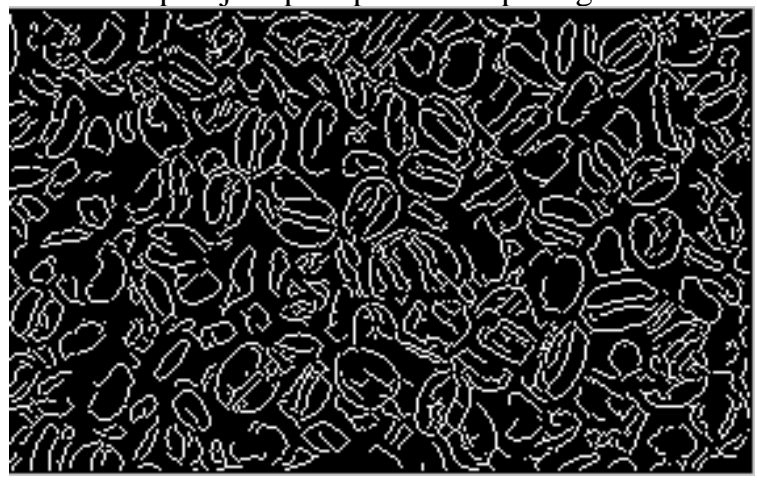

Gambar 6. Hasil Pendeteksian Tepi Biji Kopi.

\subsection{Implementasi}

Dari hasil implementasi pengujian aplikasi pengolahan citra digital untuk menentukan bibit unggul biji kopi dengan metode canny edge detection adalah sebagiai beriku:

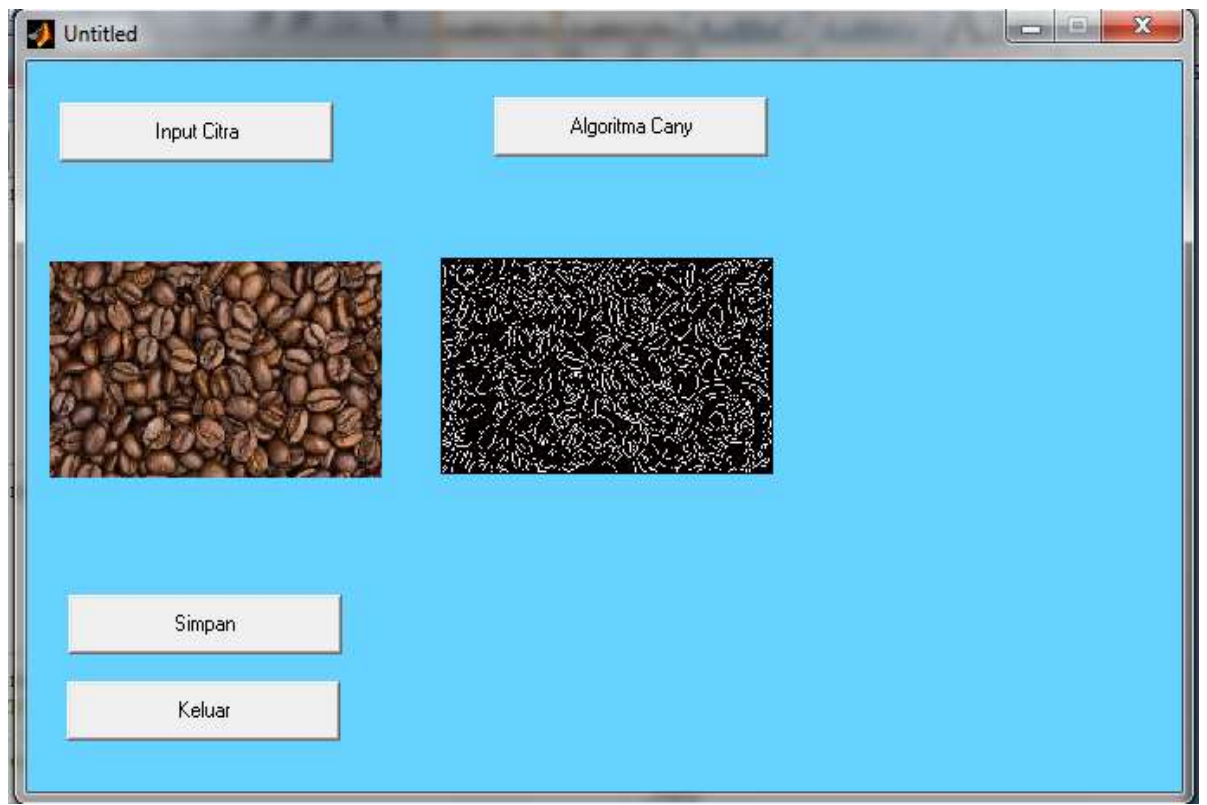

Gambar 3. Aplikasi Deteksi Tepi

\section{KESIMPULAN}

Berdasarkan analisa dan pembahasan yang dilakukan, maka dapat disimpulkan sebagai berikut :

1. Algoritma canny dapat mendeteksi tepi pada citra biji kopi.

2. Proses pengenalan untuk deteksi tepi perlu dilakukan sebelum mendeteksi objek yang penting, untuk memudahkan dalam proses deteksi tepi citra biji kopi.

3. Perancangan aplikasi dengan menggunakan software Matlab sangat memudahkan untuk mengolah dalam mendeteksi citra yang akan di proses.

\section{REFERENCES}


[1.] Abdul Kadir \& Adhi Susanto, Teori dan Aplikasi Pengolahan Citra. Yogyakarta: Andi, 2013.

[2.] T Sutoyo dkk, Teori Pengolahan Citra Digital. Yogyakarta: Andi, 2009.

[3.] Darma Putra, Pengolahan Citra Digital. Yogyakarta: Andi, 2009.

[4.] Abdul Kadir, Pengenalan Algoritma, Pendekatan Secara Visual Dan Interaktif Menggunakan Raptor (+cd). Yogyakarta: Andi, 2013.

[5.] Wahana Komputer, Ragam Aplikasi Pengolahan Image dengan Matlab. Jakarta: Elex Media Komputindo, 2013. 